\title{
Lack of effect from a single cigarette challenge on bronchial responsiveness in healthy non-smoking subjects
}

\author{
SHUNSUKE SUZUKI, FUMIHIKO SANO, JUNNICHI SUZUKI, \\ HIROYUKI NUMATA, TAKAO OKUBO
}

From the First Department of Internal Medicine, Yokohama City University School of Medicine, Yokohama, Japan

ABSTRACT The effect of smoking a cigarette on bronchial responsiveness was studied in healthy nonsmokers. Twenty two subjects performed a methacholine inhalation test before and after smoking a single cigarette. Ten of the subjects took part in a further study in which propranolol was inhaled before the smoking challenge to diminish the baseline $\beta$ adrenergic tone of the airway. After they had smoked a single filtered or non-filtered cigarette the indices of bronchial responsiveness (the cumulative dose of methacholine starting a decrease in the reciprocal of resistance, Grs (Dmin), and the cumulative dose causing a $35 \%$ drop in the $\mathrm{Grs}\left(\mathrm{PD}_{35} \mathrm{Grs}\right)$ ) did not change significantly. With the inhalation of propranolol mean (SD) log Dmin decreased from $1.37(0.44)$ units to $0.74(0.57)$ (p < $0.01)$ and $\log \mathrm{PD}_{35} \mathrm{Grs}$ from $1.93(0.38)$ to $1.51(0.38)(\mathrm{p}<0.01)$. Smoking a single cigarette after the inhalation of propranolol did not, however, cause any further change in bronchial responsiveness. This study suggests that smoking a single filtered or non-filtered cigarette does not change bronchial responsiveness in non-smokers, and that changes in $\beta$ adrenergic tone of the airway do not modify the effect of smoking a single cigarette on bronchial responsiveness.

Bronchial responsiveness to non-specific stimuli such as histamine, methacholine, and acetylcholine is increased in people with bronchial asthma and in those with chronic obstructive lung disease. ${ }^{1}$ Even in normal individuals conditions such as a viral infection of the respiratory tract, ${ }^{2}$ ozone exposure, ${ }^{3}$ and airway cooling ${ }^{4}$ influence bronchial responsiveness. What remains controversial is the effect of chronic smoking on bronchial responsiveness. ${ }^{5-8}$

Smoking a cigarette induces bronchoconstriction in small and large airways. ${ }^{910}$ In guinea pigs inhalation of cigarette smoke increased bronchial responsiveness. " It is not known, however, whether smoking one cigarette affects bronchial responsiveness in man. In the present study we have tested the hypothesis that the smoking of a single cigarette increases bronchial responsiveness.

Controversy persists on whether the $\beta$ adrenergic

Address for reprint requests: Dr S Suzuki, First Department of Internal Medicine, Yokohama City University School of Medicine, 3-46 Urafune-cho, Minami-ku, Yokohama 232, Japan.

Accepted 27 January 1988 blocker propranolol enhances bronchial responsiveness in normal individuals ${ }^{12-15}$ - propranolol is known to potentiate the effect of smoking on pulmonary function by lowering the flow rate of the maximum expiratory flow-volume curve. ${ }^{16}$ We have examined whether prior inhalation of propranolol enhances bronchial responsiveness after the smoking of a cigarette.

\section{Methods}

Twenty two healthy men whose forced expiratory volume in one second $\left(\mathrm{FEV}_{1}\right)$ was greater than $80 \%$ of predicted ${ }^{17}$ participated in the study. Their ages ranged from 24 to 32 (mean 27.3 (SD 2.4) years). The subjects were all currently non-smokers (two were ex-smokers) with no personal or family history of atopic disease, infantile eczema, rhinitis, asthma, or urticaria. No subject had any current respiratory symptoms or a history of a respiratory disease or had had a respiratory infection in the eight weeks before the study. None was taking any drugs. Informed consent was obtained from all participants. 
Before each day's study we measured the baseline forced vital capacity (FVC), $\mathrm{FEV}_{1}$, and maximum expiratory flows at $50 \%$ and $25 \%$ of FVC $\left(\dot{\mathrm{V}} \max _{50}\right.$ and $\dot{V} \max _{25}$ ), using a dry seal spirometer (Spirotest-85, Chest Co, Japan). Maximum values for each test were obtained from two or three reproducible forced expiratory curves.

Bronchial responsiveness to methacholine was measured by a continuous inhalation method. ${ }^{418}$ Initially, saline aerosols were inhaled through the mouth by tidal breathing for two minutes, followed sequentially at one minute intervals by methacholine inhalation in two fold increasing concentrations (from 0.781 to $400 \mathrm{mg} / \mathrm{ml}$ ). All aerosols were generated by the same Bird micronebuliser, driven by $5 \mathrm{l} / \mathrm{min}$ airflows. The output was $0.15 \mathrm{ml}$ of solution a minute and the particle size ranged from 0.5 to $4.0 \mu \mathrm{m}$ (manufacturer's specification). Bronchial response was measured simultaneously during aerosol inhalation by the respiratory resistance (Rrs), which was obtained by forced oscillation of this airflow superimposed on quiet tidal breathing. A $3 \mathrm{~Hz}$ sine wave oscillation generated from a loudspeaker box was directed to the subject's airway by a mouthpiece during quiet tidal breathing. The airflow was measured by a heated No 2 Fleisch pneumotachograph and a differential pressure transducer (Validyne MP-45). The Rrs was calculated by an analogue circuit from the signals of the mouth pressure and the airflow, and displayed against time on an $X-Y$ recorder (4401, Watanabe, Japan).

When Rrs reached twice that of the control Rrs, the aerosol was changed from methacholine to a bronchodilator $(0.5 \%$ salbutamol). The dose-response curve of the inhaled methacholine was evaluated by two indices of bronchial responsiveness: (1) the Dmin, being the cumulative dose of methacholine at which the reciprocal of Rrs (Grs) started to decrease from the control Grs, one unit equalling one minute of inhalation at $1.0 \mathrm{mg} / \mathrm{ml}$ during quiet tidal breathing; and (2) the $\mathrm{PD}_{35} \mathrm{Grs}$, the cumulative dose of methacholine that produced a $35 \%$ decrease in the control Grs. All methacholine inhalation tests were done at the same time of day. Values of Dmin and $\mathrm{PD}_{35} \mathrm{Grs}$ were highly correlated with $\mathrm{PD}_{35} \mathrm{Grs}$ values obtained by the conventional method (Dmin: $r=0.94$, slope $=1 \cdot 1$; $\mathrm{PD}_{35} \mathrm{Gr}: \mathrm{r}=0.98$, slope $=1.0$ unpublished observation).

\section{PROTOCOL}

Experiment 1 To study the effect on bronchial responsiveness of smoking a single filtered cigarette, we performed three methacholine inhalation tests in 13 subjects on three consecutive days (days 1,2 , and 3) within 14 days. On day 1 , after measurement of baseline lung function, a control methacholine inhala- tion test was performed. On day 2 the subject was $\stackrel{\mathbb{X}}{x}$ asked to smoke deeply a filtered cigarette containing $\vec{\Rightarrow}$ $1.1 \mathrm{mg}$ of nicotine and $16 \mathrm{mg}$ of tar within five $\stackrel{?}{?}$ minutes. Shortly after completion of smoking lung function was measured, and this was followed by a $\frac{\bar{\sigma}}{\bar{c}}$ methacholine inhalation test. On day 3 , to study the $\vec{\nabla}$ reproducibility of the methacholine inhalation test, we $\stackrel{\mathbb{}}{\varnothing}$ repeated the control methacholine inhalation test in eight of the 13 subjects in the same manner as on day $1 . \overrightarrow{0}$ Experiment 2 To investigate whether $\beta$ adrenergic blockade of the airway modifies the effects of smoking $\vec{\omega}$ on bronchial responsiveness, two methacholine inhalation tests following an inhalation of propranolol $\vec{x}$ were performed on two consecutive days (days 4 and $\vec{\omega}$ 5 ) in 10 of the 13 subjects who had participated in ir experiment 1 . This experiment was started within $f$ seven days of the end of experiment 1 . On day 4 aerosols of $3.0 \%$ propranolol (dissolved in normal 옹 saline, $\mathrm{pH}$ 6.0) were generated by a DeVilbiss $646 \overrightarrow{-}$ nebuliser, driven by $5 \mathrm{l} / \mathrm{min}$ airflows (output $0.12 \mathrm{ml} / 3$ min), and inhaled by tidal breathing for two minutes. Five minutes after inhalation of propranolol lung $\vec{\oplus}$ function was measured, and this was followed by a methacholine inhalation test. On day 5 , after inhaling propranolol in the same way as on day 4 , the subject smoked a single filtered cigarette within five minutes, and this was again followed by lung function tests and a methacholine challenge.

Experiment 3 To study the effect of smoking a nonfiltered cigarette on bronchial responsiveness, we carried out two methacholine inhalation tests in a second group of nine subjects on two consecutive days (days 6 and 7), in the same manner as in experiment 1 . On day 6 the control methacholine inhalation test was carried out after measurement of the baseline lung function. On day 7 the subject smoked a single non- $x$ filtered cigarette, containing $2 \cdot 1 \mathrm{mg}$ of nicotine and 3 . $24 \mathrm{mg}$ of tar, within five minutes. Shortly after completion of smoking the lung function was measured and the methacholine inhalation test performed.

\section{STATISTICS}

Values of Dmin and $\mathrm{PD}_{35} \mathrm{Grs}$ were expressed as logarithms and statistical analysis was performed by $\mathscr{N}$ using the paired $t$ test and one way analysis of $N$ variance.

\section{Results}

On the control day (day 1 or day 6), the FVC, FEV,$\stackrel{\oplus}{\oplus}$ $\dot{V} \max _{50}$ and $\dot{\mathrm{V}} \max _{25}$, expressed as mean (SD) $\%$ predicted, were 100.2 (8.6), 106.4 (11.1), 115.2 (29.1), 웅 and $168.0(39 \cdot 5)$. All values were within the normal $\stackrel{\mathbb{Q}}{\mathbb{Q}}$ range except in one man, whose $\dot{V}_{m a x}$ and $\operatorname{Vmax}_{25} \stackrel{\overparen{D}}{\mathbb{D}}$ were reduced despite a normal $\mathrm{FEV}_{\mathbf{1}} / \mathrm{FVC} \%$. Lung $\frac{\circ}{\sigma}$ function values before the smoking challenge did not 

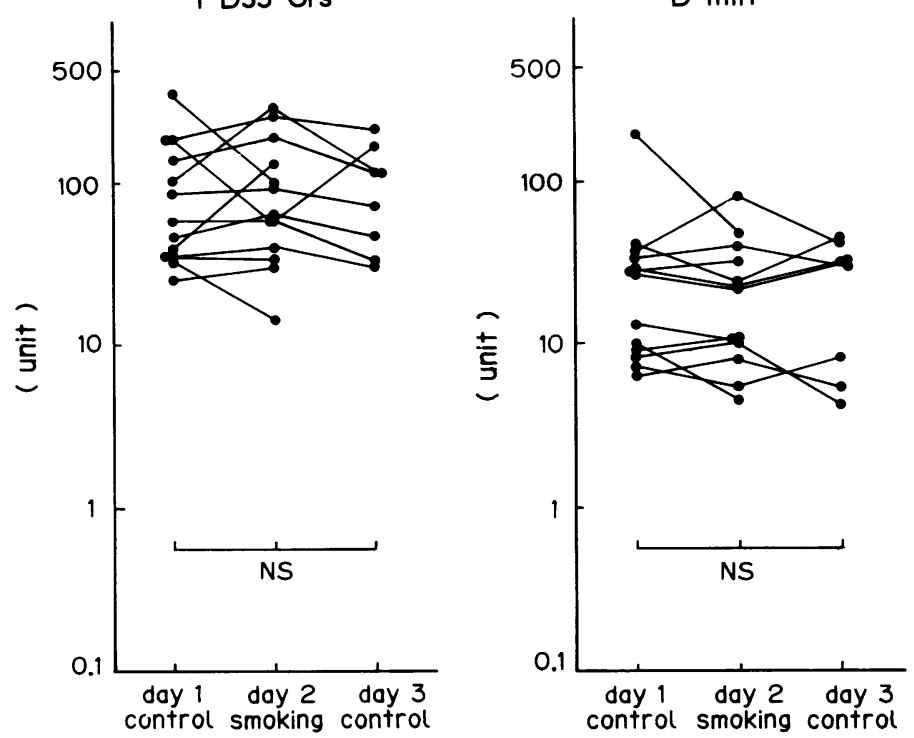

Fig 1 Acute effect of smoking a single filtered cigarette on bronchial responsiveness to methacholine $\left(P D_{35} G r s\right.$ and Dmin) in 13 non-smokers. Control measurement of bronchial responsiveness was repeated on day 3 in eight of 13 subjects; there were no differences in $P D_{35}$ Grs or Dmin between the two control days. Neither PD ${ }_{35}$ Grs nor Dmin changed after smoking a single filtered cigarette.
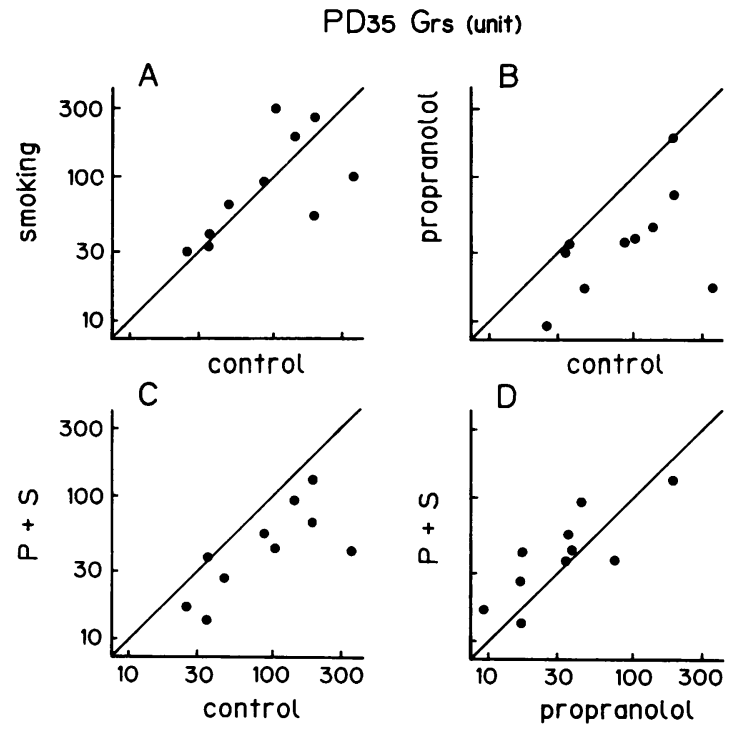

Fig 2 Effect of propranolol and smoking a single filtered cigarette on $P D_{35}$ Grs in 10 of the 13 subjects tested on days 1-5, $P D_{35}$ Grs was expressed on a logarithmic scale. The solid line is the line of identity. A-smoking v control day (day 1$)$. There was no difference in $P D_{35}$ Grs between the two days. $B$-propranolol day $v$ control day. Nine subjects had a lower $P D_{35} G r s$ on the propranolol day $(p<0.01)$. C-smoking with propranolol $(P+S)$ v control day. After smoking with propranolol $P D_{35} G r s$ values were lower than control values $(p<0.01)$. D-propranolol $v P+S$ day. Values are scattered along the line of identity and no additive effect of smoking on propranolol induced hyperresponsiveness was observed. 
Mean (SD) values for lung function and bronchial responsiveness before and after challenges

\begin{tabular}{|c|c|c|c|c|c|c|}
\hline & \multicolumn{4}{|c|}{ Lung function } & \multicolumn{2}{|c|}{ Bronchial responsiveness } \\
\hline & $\begin{array}{l}F V C \\
(l)\end{array}$ & $\begin{array}{l}F E V_{1} \\
(l)\end{array}$ & $\begin{array}{l}\dot{V} \max _{50} \\
(l / s)\end{array}$ & $\begin{array}{l}\dot{V} \max _{2 s} \\
(l / s)\end{array}$ & $\underset{\text { (unit) }}{\log D \min }$ & $\underset{\text { (unit) }}{\log P D_{35} G r s}$ \\
\hline $\begin{array}{ll}\text { Day } 2(n=13) & \begin{array}{l}\text { before FC } \\
\text { after FC }\end{array} \\
\text { Day } 4(n=10) & \begin{array}{l}\text { before Prop } \\
\text { after Prop }\end{array} \\
\text { Day } 5(n=10) & \begin{array}{l}\text { before Prop, FC } \\
\text { after Prop, FC }\end{array} \\
\text { Day } 7(n=9) & \begin{array}{l}\text { before NFC } \\
\text { after NFC }\end{array}\end{array}$ & $\begin{array}{l}4.57(0.51) \\
4.56(0.52) \\
4.50(0.57) \\
4.49(0.58) \\
4.53(0.62) \\
4.49(0.57) \\
4.83(0.44) \\
4.84(0.46)\end{array}$ & $\begin{array}{l}4.02(0.46) \\
4.00(0.47) \\
3.90(0.49) \\
3.86(0.46) \\
3.93(0.53) \\
3.76(0.51) \ddagger \\
4.45(0.56) \\
4.36(0.51) \dagger\end{array}$ & $\begin{array}{l}4 \cdot 94(1 \cdot 33) \\
4 \cdot 89(1 \cdot 30) \\
4 \cdot 70(1 \cdot 33) \\
4 \cdot 53(1 \cdot 25) \\
4 \cdot 71(1 \cdot 27) \\
4 \cdot 37(1 \cdot 19) \ddagger \\
5 \cdot 81(1 \cdot 24) \\
5 \cdot 61(1 \cdot 22) \dagger\end{array}$ & $\begin{array}{l}1.96(0.78) \\
1.94(0.67) \\
1.80(0.78) \\
1.73(0.59) \\
1.84(0.71) \\
1.78(0.60) \\
2.76(1.06) \\
2.40(0.84) \ddagger\end{array}$ & $\begin{array}{l}1.30(0.42)^{*} \\
1.24(0.38) \\
1.37(0.44)^{*} \\
0.74(0.57) \ddagger \\
1.37(0.44)^{\ddagger} \\
0.63(0.55) \ddagger \\
1.31(0.55) \S \\
1.23(0.44)\end{array}$ & $\begin{array}{l}1.86(0.36)^{*} \\
1.87(0.39) \\
1.93(0.38)^{*} \\
1.51(0.38)_{\ddagger}^{\ddagger} \\
1.93(0.38)^{*} \\
1.63(0.31)_{\ddagger}^{\ddagger} \\
1.93(0.46)^{\S} \\
1.92(0.45)\end{array}$ \\
\hline
\end{tabular}

* Both Dmin and $\mathrm{PD}_{35} \mathrm{Grs}$ were measured on day 1 and the number of the subjects differed between the test days.

$\dagger p<0.05 ; \neq p<0.01$ for differences from values before challenge.

$\S$ These were measured on day 6.

FC, smoking a single filtered cigarette; Prop, inhalation of propranolol aerosols; NFC, smoking a single non-filtered cigarette; FVC, forced vital capacity; $\dot{V} x_{50}, V \max _{25}$, maximum flow at $50 \%$ and $25 \%$ of vital capacity.

differ significantly during the five test days (days $1-5)$ or on the other two test days (6 and 7).

All subjects except the two ex-smokers complained of transient cough and nausea after smoking a single filtered cigarette. The two indices of bronchial responsiveness did not change significantly after subjects had smoked a single filtered cigarette (figs 1 and $2 A$ ). Mean (SD) $\log$ Dmin was $1.30(0.42)$ units on day 1 and 1.24 $(0.38)$ units on day 2 and $\log$ PD $_{35}$ Grs was $1.86(0.36)$ units on day 1 and $1.87(0.39)$ units on day 2 . When the control methacholine challenge was repeated in eight of the 13 subjects on day 3 neither log Dmin (1.25 (0.42) units) nor $\log \mathrm{PD}_{35} \mathrm{Grs}(1.90$ (0.32) units) differed substantially from values on day $1(1 \cdot 27(0 \cdot 35)$ and $1.95(0.28)$ units). No subject showed more than a two fold change in Dmin or $\mathrm{PD}_{35} \mathrm{Grs}$ between day 1 and day 3. Lung function was not affected by the smoking challenge (table).

Inhalation of propranolol (day 4) did not change lung function but bronchial responsiveness increased significantly (table). Mean (SD) log Dmin decreased from $1.37(0.44)$ to $0.74(0.57)$ units $(\mathrm{p}<0.01)$ and $\log$ $\mathrm{PD}_{35} \mathrm{Grs}$ decreased from $1.93(0.38)$ to $1.51(0.38)$ units ( $p<0.01$ ) (fig 2B). These changes in Dmin and $\mathrm{PD}_{35}$ Grs correspond to $4 \cdot 3$ and $2 \cdot 6$ fold decreases in threshold concentrations of methacholine. When subjects had smoked a single filtered cigarette after inhalation of propranolol (day 5), FEV $_{1}$ decreased from $3.93(0.53)$ to $3.76(0.51) 1(\mathrm{p}<0.01)$ and $\mathrm{V}_{\max }{ }_{50}$ from $4.71(1.27)$ to $4.37(1.19) \mathrm{l} / \mathrm{s}(\mathrm{p}<0.01)$. After inhalation of propranolol (day 5) $\log$ Dmin decreased from $1.37(0.44)$ units (day 1$)$ to $0.63(0.55)$ units (day $5 ; \mathrm{p}<0.01)$ and $\log \mathrm{PD}_{35}$ Grs from $1.93(0.38)$ units (day 1) to $1.63(0.31)$ units (day $5 ; \mathrm{p}<0.01$ ) (fig 2C). The decrease in Dmin correlated with the decrease in $\mathrm{PD}_{35}$ Grs $(\mathrm{r}=0.76, \mathrm{p}<0.01)$. There were no differences in Dmin or $\mathrm{PD}_{35} \mathrm{Grs}$ between day $4 \stackrel{2}{\sim}$ (pretreatment with propranolol alone) and day 5 (after $\vec{\oplus}$ the smoking of a single cigarette following propranolol) (fig 2D).

In contrast to the lack of effect of a filtered cigarette, smoking a single non-filtered cigarette (day 7) decreased mean (SD) FEV from $4.45(0.56)$ to $4.36 \%$ $(0.51) 1(\mathrm{p}<0.05), \mathrm{Vmax}_{50}$ from $5.81(1.24)$ to $5.61 \frac{\Phi}{\circ}$ $(1.22) \mathrm{l} / \mathrm{s}(\mathrm{p}<0.05)$, and $\mathrm{Vmax}_{25}$ from $2.76(1.06)$ to $\stackrel{2}{\Rightarrow}$ $2.40(0.84) \mathrm{l} / \mathrm{s}(\mathrm{p}<0.01)$. The two indices of bronchial responsiveness did not change; log Dmin was 1.31 $(0.55)$ units before (day 6) and $1.23(0.44)$ units after smoking (day 7) and $\log \mathrm{PD}_{35} \mathrm{Grs}$ was $1.93(0.46)$ units (day 6) and $1.92(0.45)$ units (day 7).

\section{Discussion}

This study shows that smoking a single filtered or non- $\delta$ filtered cigarette does not affect bronchial responsiveness to methacholine in healthy non-smokers. 윽 Although the $\beta$ adrenergic blocker propranolol $\triangle$ increased bronchial responsiveness, smoking a single을. cigarette after propranolol inhalation did not make bronchial responsiveness greater than with pro-o pranolol alone.

The smoking of three cigarettes is known to cause a N large decrease in $\mathrm{FEV}_{1},{ }^{19}$ and thus the smoking of two or more cigarettes might be expected to enhance bronchial responsiveness. In the present study the smoking challenge was limited to a single cigarette, as $\stackrel{\oplus}{-}$ the non-smokers complained of nausea or cough from 0 having to smoke a single filtered cigarette. Thus we could not increase the challenge.

We had expected that the effect on the bronchial $\frac{?}{\Phi}$ responsiveness from smoking would be increased by pretreatment with propranolol, as propranolol is 
known to potentiate the effect of smoking by a decrease in the flow rates on the maximum expiratory flow-volume curve ${ }^{16}$ and an increase in the response to acetylcholine ${ }^{13}$ or histamine. ${ }^{15}$ This, however, did not occur. Possibly the inhaled dose of propranolol in this study was too low to block the baseline $\beta$ adrenergic tone of the airway completely. Although we observed a significant effect of propranolol combined with smoking on indices of lung function, such as $F E V_{1}$, $\dot{\mathrm{V}} \max _{50}$, and $\dot{\mathrm{V}} \max _{25}$, smoking a filtered cigarette alone did not change them. Nevertheless, pretreatment with propranolol alone increased bronchial responsiveness. We think therefore that the dose of propranolol we used may have inhibited the relaxing effect of the $\beta$ adrenergic stimuli on the airway smooth muscle.

Bronchial responsiveness to methacholine has not been reported to increase after propranolol administration in normal subjects. ${ }^{1214}$ In other studies of normal subjects, however, bronchial responsiveness to acetylcholine and histamine has been increased by pretreatment with propranolol. ${ }^{1315}$ We have observed both an increase in bronchial responsiveness after propranolol and significant bronchoconstriction from smoking after pretreatment with propranolol. Zuskin et al $01^{16}$ moreover have shown that pretreatment with propranolol increases the immediate bronchoconstriction caused by smoking a cigarette. These considerations may mean that $\beta$ adrenergic blockade renders the airway hyperresponsive to both smoking and methacholine. We did not, however, observe an additive effect of smoking on bronchial responsiveness to methacholine in the airway treated with propranolol (fig 2D). As bronchoconstriction did not occur after pretreatment with propranolol, the unopposing effect of parasympathetic activity may not operate in normal individuals. The increase in bronchial responsiveness caused by propranolol may be due primarily to the abolition of the sympathetic dilator tone in the airway.

Hulbert et al have reported that during the early phase after exposure to cigarette smoke exudative changes were observed in the epithelium of guinea pigs, and that an infiltration of polymorphonuclear cells appeared six hours after exposure. ${ }^{20}$ They also found that bronchial responsiveness in guinea pigs was increased 30 minutes after exposure to cigarette smoke, ${ }^{11}$ and speculated that the increased airway permeability observed during the early phase of inflammation would increase bronchial responsiveness.

In a preliminary experiment with three subjects we performed a methacholine inhalation test 30 minutes after they had smoked a single cigarette, as Hulbert et al had observed an exudative change in the epithelium 30 minutes after exposure to cigarette smoke. We did not, however, observe any change in bronchial responsiveness. An important difference is that the dose of cigarette smoke in Hulbert's study was 100 puffs in the guinea pig, ${ }^{11}{ }^{20}$ whereas we used only one cigarette in our human subjects.

This study was supported by a grant from the Smoking Research Foundation of Japan.

\section{References}

1 Simonsson BG, Jacobs FM, Nadel JA. Role of autonomic nervous system and the cough reflex in the increased responsiveness of airways in patients with obstructive airway disease. J Clin Invest 1967;46: 1812-8.

2 Empey DW, Laitinen LA, Jacobs L, Gold WM, Nadel JA. Mechanisms of bronchial hyperreactivity in normal subjects after upper respiratory tract infection. Am Rev Respir Dis 1976;113:131-9.

3 Golden JA, Nadel JA, Boushey HA. Bronchial hyperirritability in healthy subjects after exposure to ozone. Am Rev Respir Dis 1978;118:287-94.

4 Suzuki S, Ishii M, Sasaki H, Takishima T. Bronchial responsiveness to methacholine during airway cooling in normal subjects. Clin Allergy 1986;16:33-40.

5 Brown NE, McFadden ER Jr, Ingram RH Jr. Airway responses to histamine in asymptomatic smokers and nonsmokers. J Appl Physiol 1977;42:508-13.

6 Kennedy SM, Elwood RK, Wiggs JR, Paré PD, Hogg JC. Increased airway mucosal permeability of smokers. $\mathrm{Am}$ Rev Respir Dis 1984;129:143-8.

7 Gerrard JW, Cockcroft DW, Mink JT, Cotton DJ, Poonawala R, Dosman JA. Increased nonspecific bronchial reactivity in cigarette smokers with normal lung function. Am Rev Respir Dis 1980;122:577-81.

8 Malo JL, Filiatrault S, Martin RR. Bronchial responsiveness to inhaled methacholine in young asymptomatic smokers. J Appl Physiol 1982;52:1464-70.

9 Nadel JA, Comroe JH Jr. Acute effects of inhalation of cigarette smoke on airway conductance. J Appl Physiol 1961;16:713-6.

10 Suzuki S, Sasaki H, Takishima T. Effects of smoking on dynamic compliance and respiratory resistance. Arch Environ Health 1983;38:133-7.

11 Hulbert WM, McLean T, Hogg JC. The effect of acute airway inflammation on bronchial reactivity in guinea pigs. Am Rev Respir Dis 1985;132:7-11.

12 Zaid G, Beall GN. Bronchial response to beta-adrenergic blockade. N Engl J Med 1966;275:580-4.

13 Orehek J, Gayrard P, Grimaud C, Charpin J. Effect of beta adrenergic blockade on bronchial sensitivity to inhaled acetylcholine in normal subjects. J Allergy Clin Immunol 1975;55:164-9.

14 Townley RG, McGeady S, Bewtra A. The effect of beta adrenergic blockade on bronchial sensitivity to acetylbeta-methacholine in normal and allergic rhinitis subjects. J Allergy Clin Immunol 1976;57:358-66.

15 Ploy-Song-Sang Y, Corbin RP, Engel LA. Effects of intravenous histamine on lung mechanics in man after beta-blockade. J Appl Physiol 1978;44:690-5. 
16 Zuskin E, Mttchell CA, Bouhuys A. Interaction between effects of beta blockade and cigarette smoke on airways. J Appl Physiol 1974;36:449-52.

17 Cherniack RM. Pulmonary function testing. Philadelphia: WB Saunders, 1977.

18 Takishima T, Hida W, Sasaki H, Suzuki S, Sasaki T. Direct-writing recorder of the dose-response curves of the airway to methacholine. Chest 1981;80:600-6.
19 McCarthy DS, Craig DB, Cherniack RM. The effect of $\stackrel{x}{-}$ acute, intensive cigarette smoking on maximal $\overrightarrow{\vec{F}}$ expiratory flows and the single-breath nitrogen $\stackrel{5}{-}$ washout trace. Am Rev Respir Dis 1976;113:301-4.

20 Hulbert WM, Walker DC, Jackson A, Hogg JC. Airway 흘 permeability to horseradish peroxidase in guinea pigs: $\frac{\bar{\omega}}{5}$ the repair phase after injury by cigarette smoke. $A m \mathbb{\Phi}$ Rev Respir Dis 1981;123:320-6. 